\title{
A THEORETICAL STUDY ON MOLAR FLUX IN THE CAPILLARY
}

\author{
ABDUL MALEK ${ }^{1}$ AND ASHABUL HOQUE \\ Dept. of Mathematics, University of Rajshahi, Rajhsahi-6205, Bangladesh. \\ E-mail:malekbio@gmail.com
}

\begin{abstract}
The paper is concerned with the molar flux of oxygen in the capillary blood when oxygen diffuses from blood to tissue fluid at the middle section of the capillary bed where blood pressure and osmotic pressure of blood are equal. The result shows that the molar flux decreases exponentially with the radius of the capillary. Moreover, it is found that the molar flux increases linearly with the increasing of radial diffusion of oxygen.
\end{abstract}

\section{INTRODUCTION}

Capillary-tissue fluid exchange occurs in capillary bed where blood and tissue fluids are in proximity, enclosed by endothelial cell layer that surrounds all the cells in the body. Blood moves away from the heart, branching off from arteries in arterioles, and then into capillaries where oxygen and nutrient enter the tissue fluid from the blood, and carbon dioxide and urea leave the tissue fluid to the blood. Capillary-tissue fluid exchange occurs through a membrane that is one cell thick and allows for rapid diffusion of molecules from blood to the tissue fluid and tissue fluid to blood depending on the concentration gradient. Blood pressure and osmotic pressure of blood are major factor for diffusion of molecules. Fluid exchange occurs at three steps. Theses are:

1) At the arterial end of the capillary: blood pressure is greater than the osmotic pressure of blood in this region. Thus the result is the net movement of blood plasma from capillary into the tissue fluid. That is, blood discharges oxygen and nutrients like amino acid and glucose in the plasma. The high blood pressure pushes fluid including oxygen, water, amino acid and glucose into the tissue fluid. Large molecular like red blood cell and plasma proteins cannot cross into the tissue.

2) Blood pressure is equal to the osmotic pressure of blood in the middle of a capillary bed and there is no net movement of fluid from blood to the tissue fluid. But nutrients and wastes move with their concentration gradients, which move high concentration to low concentration. In this area, oxygen and nutrients are in high concentration in the blood and they diffuse from capillary to tissue fluid through the capillary wall. On the other hand carbon dioxide and other water cells are in high concentration in the tissue fluid than capillary bed, as a result they diffuse from tissue fluid to the capillary bed.

3) At the venous end of the capillary bed: osmotic pressure of blood is greater than the blood pressure and the result is a net movement of tissue fluid back to the blood. Thus additional amount of dissolved carbon dioxide, urea, uric acid and other tissue fluid move from tissue fluid to capillary bed.

The transport of molecules (oxygen and nutrients) from capillary blood plasma to tissue fluid through capillary wall are all based on the Krogh's cylinder model, $\operatorname{Krogh}^{(1)}$. The assumptions are, all capillaries and surrounding tissue are equal diameters and are

\footnotetext{
${ }^{1}$ Corresponding auther: malekbio@gmail.com
} 
REVERSIBLE LOGIC SYNTHESIS OF FAULT TOLERANT CARRY SKIP BCD

homogeneously dispersed in the tissue. Transport of oxygen in the capillary region depends on convection, diffusion and rate of generation of oxygen due to the dissociation of oxyhemoglobin. In the tissue region, there is diffusion of oxygen and consumption of oxygen by the tissue cells. Bird et al. ${ }^{(2)}$ suggested that temperature gradients and external force also contribute to the diffusion flux, although their effects are usually minor. Brid et al. ${ }^{(3)}$ also suggested that Fick's equation evaluates diffusion as a flux " measured with respect to the motion of the center of mass ". Since Fick's law equates diffusion to a gradient relative to the external coordinates. Due to the low Peclet number in capillary blood flow, convective transport can be neglected, Aroesty et al. ${ }^{(4)}$. Ellsworth et al. ${ }^{(5)}$ has been developed for use in capillaries in striated muscle but should be generally applicable to the measurement of capillary oxygen saturation in other tissues.

From the above literature, we can see that all the study of molar flux regarding $\mathrm{O}_{2}$ diffusion concentrated experimentally but we have tried to find out theoretically the fluid exchange at the middle section of capillary bed where blood pressure and osmotic pressure of blood are equal and materials move by diffusion.

\section{MATHEMATICAL FORMULATION}

Oxygen transport in the capillary occurs by passive diffusion. According to Krogh's cylinder model in capillary region, the transport of oxygen depends on diffusion, convection, and rate of generation of oxygen to the dissociation of oxyhemoglobin. The mathematical expression of above model becomes

$$
\frac{D c}{D t}=D_{b}\left(\frac{\partial^{2} c}{\partial r^{2}}+\frac{1}{r} \frac{\partial c}{\partial r}+\frac{\partial^{2} c}{\partial z^{2}}\right)+d(c)
$$

where $c$ is the concentration of oxygen, $D_{b}$ is the diffusion coefficient of oxygen in blood as the harmonic mean of hemoglobin and plasma diffusion coefficients. $d$ (c) be the rate of generation of oxygen to the dissociation of oxyhemoglobin. $\frac{D}{D t}$ stands for connective derivative expressed as

$$
\frac{D}{D t}=\frac{\partial}{\partial t}+v \frac{\partial}{\partial z}
$$

where $v$ is the velocity of the blood.

But rate of generation of oxygen to the dissociation of oxyhemoglobin can be expressed as

$$
d(c)=-N\left(\frac{D S}{D t}\right)
$$

where $N$ is the oxygen bounding capacity of blood, and $S$ is the oxygen saturation. By Hill's equation for oxygen saturation $S$ in terms of partial pressure $p$ is

$$
S=\frac{p^{n}}{p^{n}+p_{50}^{n}}
$$

where $p$ is the partial pressure of oxygen and $p^{n}$ denotes the partial pressure at $50 \%$ oxyhemoglobin saturation. Considering normal human blood at $37^{0} C$ and $p^{H}=7.4$, the derived constant $p_{50}$ is $26 \mathrm{mmHg}$ and $n$ is 2.7 . 
228REVERSIBLE LOGIC SYNTHESIS OF FAULT TOLERANT CARRY SKIP BCD

The relation between partial pressure and concentration of a dissolved gas in the liquid is described called Henry's law:

$$
c=\alpha p
$$

where $\alpha$ is solubility coefficient.

After simplifying Eqs. (3) and (4), we obtain

$$
S=\frac{c^{n}}{c^{n}+\left(\alpha p_{50}\right)^{n}}
$$

Therefore Eq. (1) becomes

$$
\frac{D}{D t}\left(c+N\left(\frac{c^{n}}{c^{n}+(\alpha p)^{n}}\right)\right)=D_{b}\left(\frac{\partial^{2} c}{\partial r^{2}}+\frac{1}{r} \frac{\partial c}{\partial r}+\frac{\partial^{2} c}{\partial z^{2}}\right)
$$

Due to the low Peclet number in capillary blood flow, we can neglect the convective transport. Axial diffusion also is neglected because of the ratio of the magnitude of the term containing axial diffusion and the magnitude of the term contain radial diffusion is usually very less then one. Then Eq. (6) becomes

$$
\frac{\partial}{\partial t}\left(c+N\left(\frac{c^{n}}{c^{n}+\left(\alpha p_{50}\right)^{n}}\right)\right)=D_{r}\left(\frac{\partial^{2} c}{\partial r^{2}}+\frac{1}{r} \frac{\partial c}{\partial r}\right)
$$

where $D_{r}$ is the radial diffusion coefficient of oxygen.

The concentration gradient is obtained from Eq. (7) as steady state case, that is, neglect the time dependent term as

$$
D_{r}\left(\frac{\partial^{2} c}{\partial r^{2}}+\frac{1}{r} \frac{\partial c}{\partial r}\right)=0 \quad \text { where } \quad r_{0} \leq r \leq r_{i}
$$

We can find the concentration gradient from Eq. (8) by using the following boundary conditions

$$
\begin{aligned}
& c=c_{0} \text { at } r=r_{0} \\
& c=c_{i} \text { at } r=r_{i}
\end{aligned}
$$

where $c_{o}$ and $c_{i}$ are the concentrations of oxygen at $r_{o}$ and $r_{i}$ respectively.

After simplifying Eq. (8), using the boundary conditions, we obtain

$$
\frac{\partial c}{\partial r}=\frac{c_{0}-c_{i}}{r \log \frac{r_{0}}{r_{i}}}
$$

We can obtain molar flux $J_{r}$ in the capillary blood by using the Fick's first law of diffusion, which is proportional to concentration gradient. That can be expressed as

$$
J_{r}=-D_{r} \frac{\partial c}{\partial r}
$$


REVERSIBLE LOGIC SYNTHESIS OF FAULT TOLERANT CARRY SKIP BCD

The negative sign indicates that, concentration increases in the opposite direction of net molar flux. Thus

$$
J_{r}=-D_{r} \frac{c_{0}-c_{i}}{r \log \frac{r_{0}}{r_{i}}}
$$

Since all capillaries are equal diameter. So we integrate both sides of Eq.(10) from $r_{0}$ to $r_{i}$, getting

$$
J_{r}=\frac{D_{r}}{r_{i}-r_{0}}\left(c_{0}-c_{i}\right) \text { or, } \frac{J_{r}}{\left(c_{0}-c_{i}\right)}=\frac{D_{r}}{r}
$$

This is the required model for finding the molar flux verses concentration in the capillary taking $r_{i}-r_{0}=r$.

\section{SUMMARY AND CONCLUDING REMARKS}

The molar flux in capillary blood has been studied theoretically. We considered partial differential equation for capillary region and neglected convective and axial diffusion of $\mathrm{O}_{2}$ from this equation based on small Peclet number and Fick's first law that produced Eq. (11). Figure (2) which is derived from Eq. (11), shows the molar flux $\left(J_{r} /\left(c_{0}-C_{i}\right)\right)$ decreases with the increasing of radial distance of the capillary for different values diffusion coefficient of oxygen $\left(D_{r}\right)$ in blood. Similar trend of the graph can be found using the values of different diffusion coefficient measured by several researchers (Fig. 4). On the other hand, Fig (3) shows that the molar flux increases linearly with the diffusion coefficient. In Fig. (2), $J_{r} /\left(c_{0^{-}}\right.$ $c_{i}$ ) can be seen maximum at $r \rightarrow 0$. If $J_{r} /\left(c_{0}-C_{i}\right)$ goes to zero as $r \rightarrow \propto$ then at some point the oxygen molar flux will be zero. Otherwise if $\left(c_{0}-c_{i}\right)=0$ i.e. there is no concentration difference then Eq.(11) shows that, there is no molar flux along the axial axis of the capillary. This suggests that there must be concentration difference, implying that partial pressure difference (by Henry's law) for diffusion of oxygen (gas), otherwise diffusion does not occur. We can conclude the effect of the radial distance of the capillary on the expression $J_{r} /\left(C_{0}-C_{i}\right)$, since that is inversely proportional to the radius. Eq. (11) also suggests that for diffusion, there must be a membrane between the two medium, since above equation does not exist at $r$ $=0$.

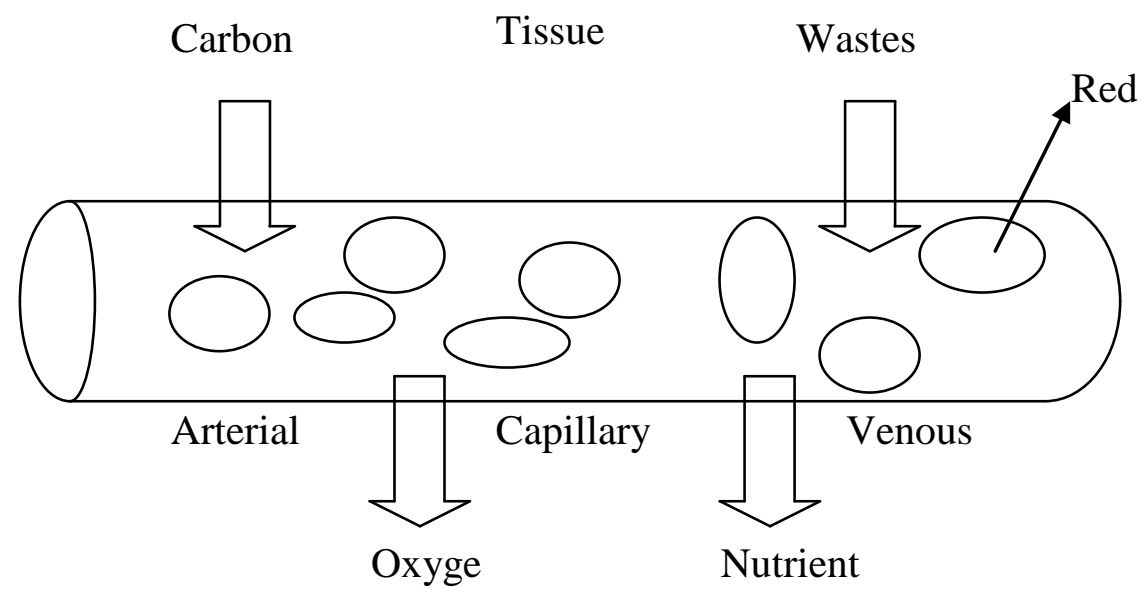


230REVERSIBLE LOGIC SYNTHESIS OF FAULT TOLERANT CARRY SKIP BCD

Figure 1: Exchange of fluids across the capillary wall between capillary blood and tissue fluid at the middle section of the capillary bed during diffusion.

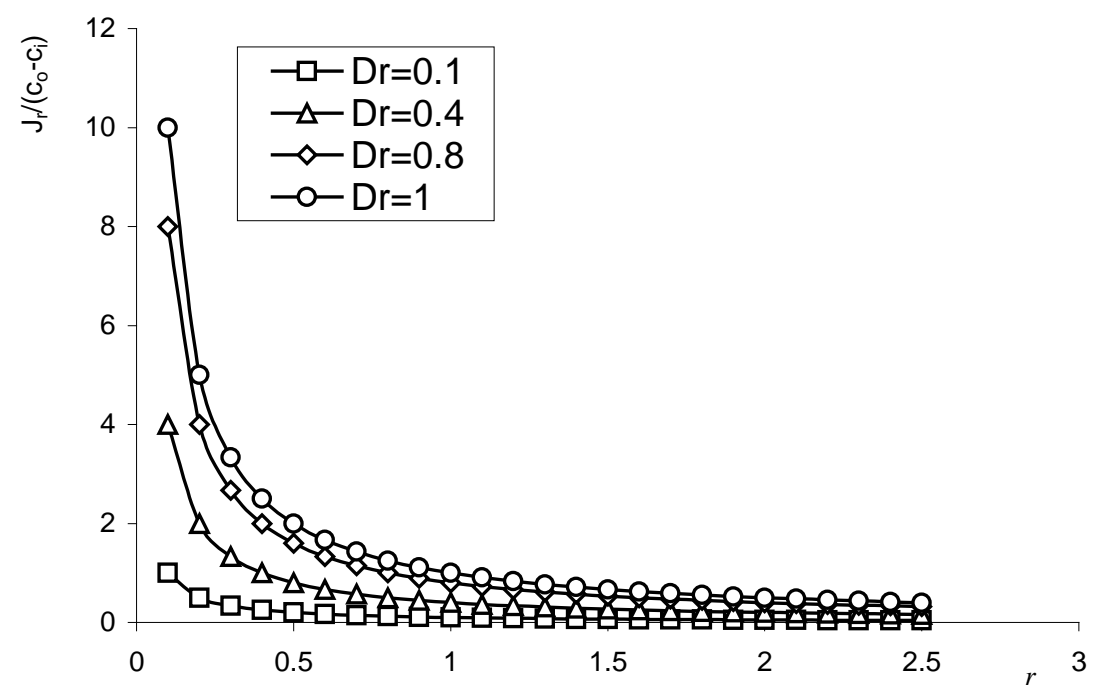

Figure 2: Effect of radial distance on molar flux. 


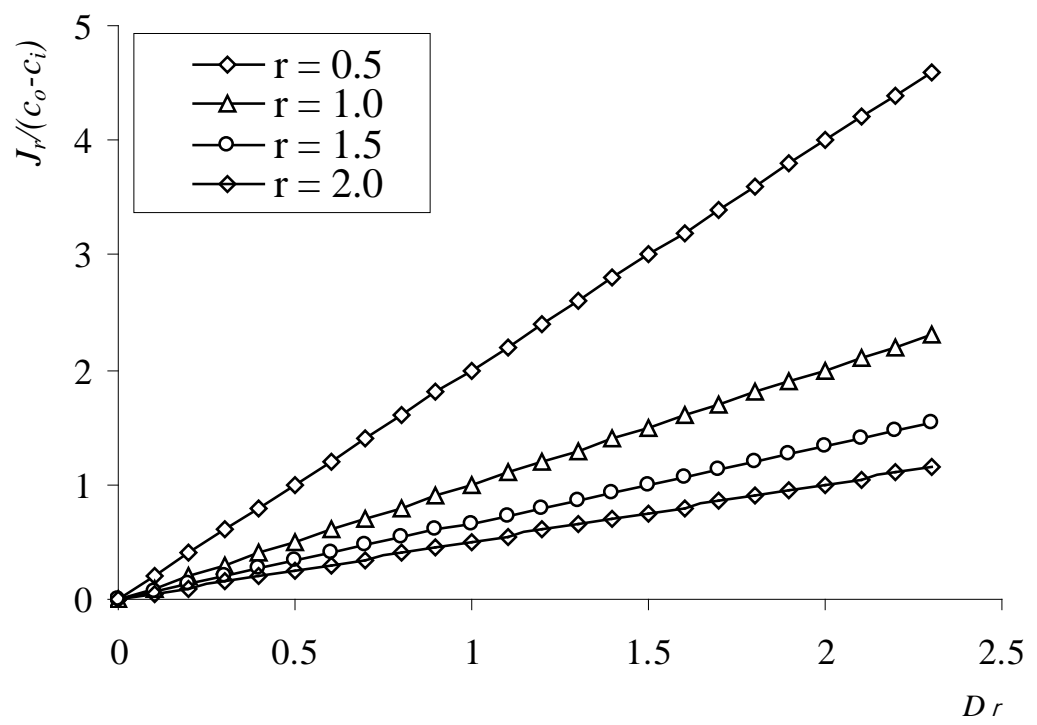

Figure 3: Effect of diffusion coefficient of oxygen on molar flux.

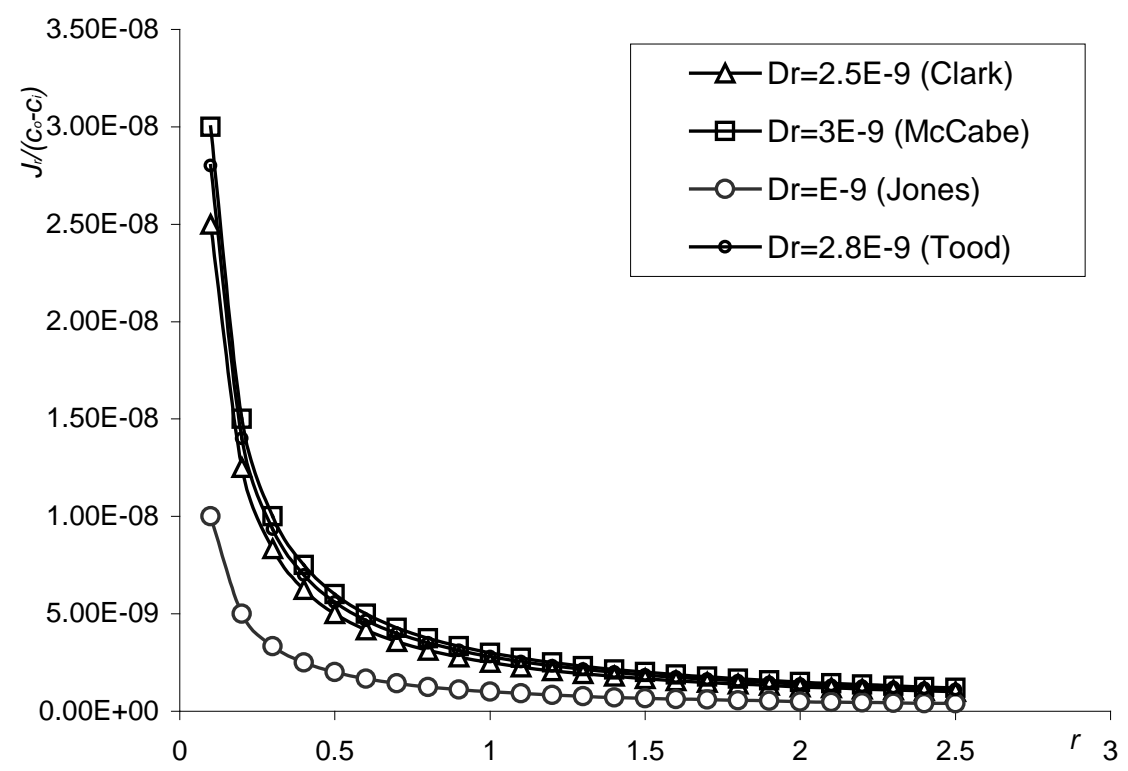

Figure 4: Effect of radial distance on molar flux for diffusion coefficients measured by several researchers.

In general the diffusion coefficient of oxygen through tissue appeared to be equal to that of through water by the fraction of the tissue composed of water. Several researchers (Rashevsky $^{(6)}$, Jones and Kennedy ${ }^{(7)}$, Jones ${ }^{(8)}$, Clark $^{(9)}$, etc.) used different values of diffusion coefficient that is mentioned in Table 1.

Table 1: Different values of diffusion coefficient of oxygen in different tissues by several researchers. 
232REVERSIBLE LOGIC SYNTHESIS OF FAULT TOLERANT CARRY SKIP BCD

\begin{tabular}{lll}
\hline \multicolumn{1}{c|}{ Researcher } & \multicolumn{1}{c}{ Diffusion Coefficient For } & \multicolumn{1}{c}{ Values } \\
\hline Jones and Kennedy ${ }^{(7)}$ & Tissue during hypoxia & $7 \times 10^{-12} \mathrm{~m}^{2} \mathrm{~s}^{-1}$ \\
Todd et al. ${ }^{(10)}$ & Water & $2.8 \times 10^{-9} \mathrm{~m}^{2} \mathrm{~s}^{-1}$ \\
Todd et al. $^{(10)}$ & Blood & $1.8 \times 10^{-9} \mathrm{~m}^{2} \mathrm{~s}^{-1}$ \\
Jones $^{(8)}$ & Tissue & $10^{-9} \mathrm{~m}^{2} \mathrm{~s}^{-1}$ \\
Clark et al. $^{(9)}$ & Bovine \& murine cumulus oocyte & $2.5 \times 10^{-9} \mathrm{~m}^{2} \mathrm{~s}^{-1}$ \\
Rashevsky $^{(6)}$ & Protoplasm & $11.66 \times 10^{-9} \mathrm{~cm}^{2} \mathrm{~min}^{-1}$ \\
Andrew et al. ${ }^{(11)}$ & Nafion membrane 1 & $5.8692 \times 10^{-7} \mathrm{~cm}^{2} \mathrm{~s}^{-1}$ \\
Andrew et al. ${ }^{(11)}$ & Nafion membrane 2 & $6.4306 \times 10^{-7} \mathrm{~cm}^{2} \mathrm{~s}^{-1}$ \\
Andrew et al. ${ }^{(11)}$ & Cape cod membrane 1 & $4.2231 \times 10^{-7} \mathrm{~cm}^{2} \mathrm{~s}^{-1}$ \\
Andrew et al. ${ }^{(11)}$ & Cape cod membrane 2 & $3.9445 \times 10^{-7} \mathrm{~cm}^{2} \mathrm{~s}^{-1}$ \\
\hline
\end{tabular}

\section{REFERENCES}

1. Krogh A. (1919): The rate of diffusion of oxygen through animal tissue, J Phys, 391-408.

2. Bird R.B, W.E. Stewart and E.N. Lightfoot (1960): Transport phenomena, John Wiley \& Sons, New York.

3. Bird R.B, W.E. Stewart and E.N. Lightfoot (2002): Transport phenomena, John Wiley \& Sons, New York.

4. Aroesty J. and J.F. Gross (1970): Convection and diffusion in the microcirculation, M. crovast Res, 2(3), 247267.

5. Ellsworth M.L, R.N. Pittman and C.G. Ellis (1987): Measurement of hemoglobin oxygen saturation in capillaries, Am J Physiol Heart Circ Physiol, 252, H1031-H1040, 0363-6135/87.

6. Rashevsky N. (1933): Note on the mathematical theory of oxygen consumption at low oxygen pressure, Protoplasma, Springer Wien, 20,125-130.

7. Jones D.P. and Kennedy F.G. (1982): Intercellular oxygen supply during hypoxia, American Journal of Physiology, Cell physiology, 243, c.247-c.253.

8. Jones D.P. (1986): Intracellular diffusion gradients of $\mathrm{O}_{2}$ and ATP, American Journal of Physiology, Cell physiology, 250, c.663-c.675.

9. Clark A.R, Stokes Y.M, M. Lane and J.G. Thompsion (2006): Mathematical modeling of oxygen concentration in bovine and murine cumulus-oocyte complexes, Reproduction, 131, 999-1006.

10. Todd J. Hewtt, Brack G, and William J. Federspiel (1998): A mathematical model of gas exchange in an intravenous membrane oxygenation, Annals of Biomedical Engineering, 26, 166-178.

11. Andrew T. Haug and Ralph, E. White (2000): Oxygen diffusion coefficient and solubility in a new proton exchange membrane, Journal of the Electrochemical Society, 147 (3), 980-983.

12. Dr. Jakubowski (2006): Chapter 6- Transport and kinetics, A- passive and facilitated diffusion. (Biochemistry online).

13. Kapur J.N. (1985): Mathematical models in Biology and Medicine, Affiliated East-West Press Private Limited, India.

14. Srinivasan R. Srini, Wayne A. Gerth, and Michael R. Powell (1999): Mathematical model of diffusion -limited gas bubble dynamics in tissue, J Appl Physiol, 82(2), 732-741. 
REVERSIBLE LOGIC SYNTHESIS OF FAULT TOLERANT CARRY SKIP BCD

15. Andreas O. Frank, C. J. Charles Chuong, and Robet L. Johnson (1997): A finite- element model of oxygen diffusion in the pulmonary capillary, J Appl Physio, 82, 2036-2044.

Journal of Bangladesh of Sciences, Vol. 32, No. 2, 175-182, 2008 